\title{
Water-Soluble 2-Methacryloyloxyethyl Phosphorylcholine Copolymer as a Novel Synthetic Blocking Reagent in Immunoassay System
}

\author{
Shujirou SAKAKI, Yasuhiko IWASAKI, Nobuo NAKABAYASHI, and \\ Kazuhiko ISHIHARA* \\ Institute of Biomaterials and Bioengineering, Tokyo Medical and Dental University, \\ 2-3-10, Kanda-Surugadai, Chiyoda-ku, Tokyo 101-0062, Japan \\ * Department of Materials Science, Graduate School of Engineering, \\ The University of Tokyo, 7-3-1, Hongo, Bunkyo-ku, Tokyo 113-8656, Japan
}

(Received November 30, 1999)

\begin{abstract}
The purpose of this study is the development of a novel synthetic blocking reagent for the enzymelinked immunosorbent assay (ELISA) method. The water-soluble amphiphilic phospholipid polymer, poly[2methacryloyloxyethyl phosphorylcholine (MPC)-co-styrene (St)], was synthesized, and the function of the poly(MPC-coSt) as a blocking reagent was compared with conventional blocking reagents which are made of proteins such as bovine serum albumin (BSA) and casein. The poly(MPC-co-St) solution functioned at the same level as BSA solution and casein solution for preventing non-specific antibody adsorption $(p>0.01)$. When the $1.0 \mathrm{wt} \%$ BSA solution and $1.0 \mathrm{wt} \%$ casein solution were used as a blocking reagent, the remaining activity of the immobilized antibody decreased about $50 \%$ after 20 days. On the other hand, in $0.01 \mathrm{wt} \%$ and $0.1 \mathrm{wt} \%$ poly(MPC-co-St) solutions, the activity remained $76 \%$ and $91 \%$ of the initial value, respectively. The effects of poly(MPC-co-St) on the stabilization of the immobilized antibody depended on its concentration. These results indicated that the poly(MPC-co-St) had the ability to inhibit denaturation of protein, that is, proteins in the ELISA system kept their native structure. We concluded that the water-soluble amphiphilic poly(MPC-co-St) is an effective synthetic blocking reagent in the ELISA method. KEY WORDS 2-Methacryloyloxyethyl Phosphorylcholine/Poly(methacryloyloxyethyl phosphoryline-costyrene)/ Synthetic Blocking Reagent/
\end{abstract}

The use of enzyme as a label molecule has many advantages over the use of the other kind of label molecules in both immunohistochemistry and immunoassay. In immunohistochemistry, an antibody conjugated with enzyme (enzyme-antibody conjugate) permits localization and demonstration of cellular antigens in relation to tissue structures by optical microscopy and electromicroscopy. ${ }^{1-3}$ For detecting or quantification of an analyte (a very small amount of physiologically active molecule), an immunological measurement can be effectively used. The enzyme-linked immunosorbent assay (ELISA) for the measurement of antigen using an immobilized antibody and enzyme-antibody conjugate is known as the sandwich immunoassay technique. ${ }^{4,5}$ This method is very widely used because it can be easily applied with high sensitivity. However, in the ELISA method, nonspecific adsorption of the enzyme-antibody conjugate on the solid phase induces a significantly decreased measurement reliability. Accordingly, in the sandwich method, a blocking reagent is necessary to restrain nonspecific adsorption of the enzyme-antibody conjugate, which is first purpose of the blocking reagent. The other immunological measurement methods needing a blocking reagent are radioimmunoassay (RIA), western blot technique, immunospecific tissue staing and flowcytometry. Actually, when polystyrene (poly $(\mathrm{St})$ ) particles are used as the solid phase and bovine serum albumin (BSA) is used as a blocking reagent, it is known that $0.10 \%-0.11 \%$ of antibody conjugated with horseradish peroxidase (HRP-antibody conjugate) is non-specifically adsorbed on the poly(St) particles. ${ }^{6-8}$ In the sandwich method using the immobilized antibody, after immobilizing of antibody onto the solid phase, the other protein which has no influence on the immunological and enzymatic reaction is added to the solid phase. The second purpose of the blocking reagent is stabilization of the immobilized antibody. When the immobilized antibody is not stable, the reproducibility of the biological assay should be decreased. In general, BSA, ovalbumin, casein, and serum (containing proteins) are used as blocking reagents for the prevention of non-specific adsorption and stabilization of the immobilized antibody. However, these blocking reagents have serious problems, that is, denaturation after a long preservation period or repeatedly freezing and melting.

The polymers having phospholipid polar groups, 2methacryloyloxyethyl phosphorylcholine (MPC) polymers, are well known for the suppression of protein adsorption ${ }^{9}$ and denaturation on the surface. ${ }^{10}$ In our previous article, ${ }^{11}$ water-soluble poly(MPC-co-St) stabilizes the antibody conjugated with horseradish peroxidase (HRP-antibody conjugate). In this study, the watersoluble amphiphilic poly(MPC-co-St) was examined as the blocking reagent in ELISA.

\section{EXPERIMENTAL}

\section{Synthesis of Water-Soluble MPC Polymer}

MPC was synthesized by a previously reported method and purified by recrystallization from acetonitrile. ${ }^{12} \mathrm{St}$ and $t$-butyl peroxy pivalate were commercial reagent grade. All other reagents were extra-pure re- 
Table I. Synthetic results of poly(MPC-co-St)

\begin{tabular}{|c|c|c|c|c|c|}
\hline \multicolumn{2}{|c|}{ Mole fraction of MPC } & \multirow{2}{*}{$\frac{\text { Yield }^{\mathrm{b}}}{\%}$} & \multirow{2}{*}{$M_{n} \times 10^{-5 \mathrm{c}}$} & \multirow{2}{*}{$M_{w} \times 10^{-5 \mathrm{c}}$} & \multirow{2}{*}{$M_{w} / M_{n}{ }^{c}$} \\
\hline In feed & In copolymer $^{a}$ & & & & \\
\hline 0.50 & 0.62 & $85: 0$ & 1.0 & 1.6 & 1.6 \\
\hline
\end{tabular}

agent grade. The random copolymer of MPC and St, poly(MPC-co-St), was prepared by a conventional radical polymerization technique in ethanol using $t$-butyl peroxy pivalate as the initiator. ${ }^{13}$ The chemical structure of poly(MPC-co-St) was confirmed with ${ }^{1} \mathrm{H}$ NMR (JNM-EX 270, JEOL, Tokyo, Japan) in $\mathrm{D}_{2} \mathrm{O}$. Gel permeation chromatography (TSKgel G $400 \mathrm{PW}_{\mathrm{XL}}$ and TSKgel G $300 \mathrm{PW}_{\mathrm{XL}}$, TOSOH, Tokyo, Japan) was used to determine the number-average molecular weight $\left(M_{n}\right)$ and the weightaverage molecular weight $\left(M_{w}\right)$ of the poly(MPC-co-St) in $20 \mathrm{mM}$ sodium phosphate buffer ( $\mathrm{pH} 7.4$ ) with poly(ethylene oxide) standards. The chemical structure of the poly(MPC-co-St) and the synthetic results are given in Figure 1 and Table I, respectively.

\section{Surface Tension Measurement of Poly(MPC-co-St) Aque ous Solution}

The surface tension of an aqueous solution containing poly(MPC-co-St) was determined with a surface tension meter (DCA-100, ORIENTEC, Tokyo, Japan) based on the Wilhelmy plate method. Double-distilled water was used to prepare the polymer solution.

\section{Measurement of the Amounts of Non-Specific Adsorption of Enzyme-Antibody Conjugate}

A poly(St) microtiter plate (Nunc Maxisorp F 96, Nunc, New York, U.S.A.) was used as the solid phase, anti(mouse IgG)goat IgG (Lampire Biological Lab., Pennsylvania, U.S.A.) was used as the immobilized antibody, mouse IgG (Lampire Biological Lab., Pennsylvania, U.S.A.) was used as the antigen, and anti(mouse IgG)goat IgG conjugated with HRP (HRP-IgG conjugate) (Wako, Osaka, Japan) was used as the enzyme-antibody conjugate. BSA (Sigma, Missouri, U.S.A.) and casein (from bovine milk, Sigma, Missouri, U.S.A.) were commercial reagent grade and used without further purification. $O$-Phenylenediamine hydrochloride (OPD) (Wako, Osaka, Japan) was used as a substrate of HRP.

To immobilize the antibody on the solid phase, $100 \mu \mathrm{L}$ anti(mouse IgG)goat IgG solution $\left(10 \mu \mathrm{g} \mathrm{mL}^{-1}\right.$ in $0.1 \mathrm{M}$ sodium phosphate buffer, $\mathrm{pH}$ 7.4) was pipetted into each well of the microtiter plate, and then the microtiter plate was sealed with an adhesive strip and incubated at $4{ }^{\circ} \mathrm{C}$ overnight. After incubation, the anti(mouse IgG)goat IgG solution was aspirated from each well. To remove the unimmobilized IgG, the well was washed four times with $300 \mu \mathrm{L}$ phosphate-buffered saline (PBS, pH 7.4). After washing, to prepare microtiter plate blocked by various blocking reagents, one of the PBS solutions containing $0.01 \mathrm{wt} \%$ poly(MPC-co-St), $1.0 \mathrm{wt} \% \mathrm{BSA}$ and $1.0 \mathrm{wt} \%$ casein was pipetted into each well $(300 \mu \mathrm{L} / \mathrm{each}$ well), and then the microtiter plate was sealed with an adhesive strip and incubated at $4^{\circ} \mathrm{C}$ overnight. After incubation the solutions were removed from each well. For

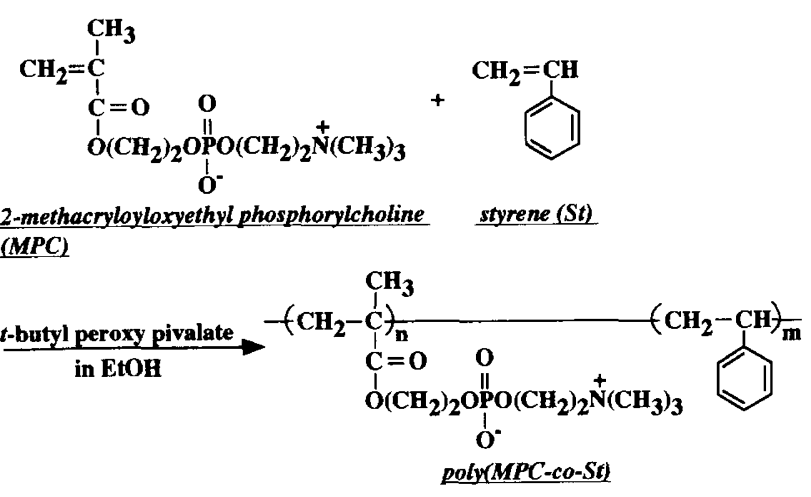

Figure 1. Chemical structure of poly(MPC-co-St).
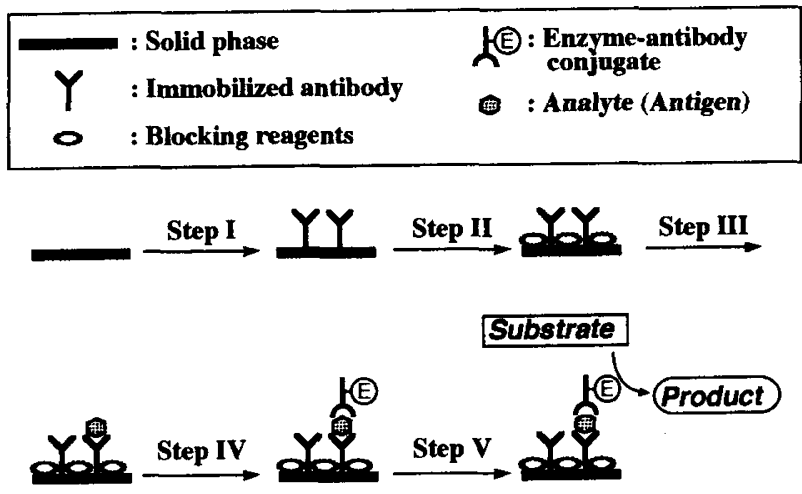

Figure 2. ELISA procedure determined activity of immobilized antibody.

measurement of the amount of the non-specific adsorption of HRP-IgG conjugate, the following process was carried out. The HRP-IgG conjugate solution was diluted with PBS containing 5.0 wt\% BSA (dilution was $1: 10000$ ). One hundred microliters of the diluted HRPIgG conjugate solution was pipetted into each well, and then the microtiter plate was sealed with an adhesive strip and incubated at $4^{\circ} \mathrm{C}$ overnight. After incubation, the diluted HRP-IgG conjugate solution was aspirated from each well, and then the microtiter plate was washed four times with PBS. To prepare the substrate solution, $6 \mathrm{mg}$ OPD was dissolved in a $15 \mathrm{~mL}$ aqueous solution containing $50 \mathrm{mM} \mathrm{Na} \mathrm{HPO}_{4}, 24 \mathrm{mM}$ citric acid, and $0.006 \% \mathrm{H}_{2} \mathrm{O}_{2}$. One hundred microliters of the OPD solution was pipetted into each well, and incubated at $25^{\circ} \mathrm{C}$ for $10 \mathrm{~min}$. After incubation, to stop the reaction, $50 \mu \mathrm{L}$ of $2 \mathrm{~N} \mathrm{H}_{2} \mathrm{SO}_{4}$ was pipetted into each well. Absorbance at $492 \mathrm{~nm}$ was measured using a microtiter plate reader (MPRA-4 i, TOSOH, Tokyo, Japan).

\section{Effect of Blocking Reagents on the Amount of Product}


In Figure 2, the procedure used in this study is shown. As step I, to immobilize the antibody on the solid phase, $100 \mu \mathrm{L}$ anti(mouse IgG)goat IgG solution $\left(10 \mu \mathrm{g} \mathrm{mL}^{-1}\right.$ in $0.1 \mathrm{M}$ sodium phosphate buffer, $\mathrm{pH} 7.4$ ) was pipetted into each well of the microtiter plate, and then the microtiter plate was sealed with an adhesive strip and incubated at $4^{\circ} \mathrm{C}$ overnight. After incubation, the anti(mouse IgG)goat IgG solution was aspirated from each well. To remove the unimmobilized IgG, the well was washed four times with $300 \mu \mathrm{L}$ phosphate-buffered saline (PBS, $\mathrm{pH}$ 7.4). After washing, to prepare the microtiter plate blocked by various blocking reagents (Step II), one of the PBS solutions containing 0.01 wt\% poly(MPC-co-St), $0.1 \mathrm{wt} \%$ poly(MPC-co-St), $1.0 \mathrm{wt} \% \mathrm{BSA}$ and $1.0 \mathrm{wt} \%$ casein was pipetted into each well $(300 \mu \mathrm{L}$ each well), and then the microtiter plate was sealed with an adhesive strip and incubated at $4^{\circ} \mathrm{C}$ overnight. The solution was removed from each well, and the microtiter plate was lyophilized to maintain the activities of the immobilized antibody. To measure the activities of the immobilized antibody, $100 \mu \mathrm{L}$ of $1.0 \mu \mathrm{g} \mathrm{mL} \mathrm{mouse}^{-1}$ mous IgG solution dissolved in PBS containing $0.5 \mathrm{wt} \% \mathrm{BSA}$ was pipetted into each well, and then the microtiter plate was sealed with an adhesive strip and incubated at $4^{\circ} \mathrm{C}$ overnight (Step III). The solution was removed from the well, and the microtiter plate was washed four times with PBS. One hundred microliters of the diluted HRPIgG solution was pipetted into each well, and the microtiter plate was then sealed with an adhesive strip and incubated at $4^{\circ} \mathrm{C}$ overnight (Step IV). The HRP-IgG solution was aspirated from each well, and the microtiter plate was then washed with PBS four times. One hundred microliters of the OPD solution was pipetted into each well and incubated at $25^{\circ} \mathrm{C}$ for $10 \mathrm{~min}$ (Step V). To stop the enzyme reaction, $50 \mu \mathrm{L}$ of $2 \mathrm{~N} \mathrm{H}_{2} \mathrm{SO}_{4}$ was added to each well. Absorbance at $492 \mathrm{~nm}$ was measured using a microtiter plate reader (MPRA-4i, TOSOH, Tokyo, Japan).

Measurement of the Remaining Activities of Immobilized Antibody

After the microplate which was blocked by various blocking reagents (one of the PBS solutions containing $0.01 \mathrm{wt} \%$ poly(MPC-co-St), $0.1 \mathrm{wt} \%$ poly(MPC-co-St), $1.0 \mathrm{wt} \% \mathrm{BSA}$ and $1.0 \mathrm{wt} \%$ casein) was stored at $40^{\circ} \mathrm{C}$ for a period of 20 days to measure the remaining activities of the immobilized antibody, the operations were carried out in the same way to determine the effect of blocking reagents on the amount of product.

\section{RESULTS AND DISCUSSION}

\section{Synthesis of Water-Soluble MPC Polymer}

The copolymerization proceeded homogeneously in ethanol. Table I summarizes the results of the copolymerization of MPC with St. The chemical structure of poly(MPC-co-St) was confirmed by ${ }^{1} \mathrm{H}$ NMR, that is, the peaks assigned to $\alpha-\mathrm{CH}_{3}(0.95 \mathrm{ppm}),-\mathrm{N}^{+}\left(\mathrm{CH}_{3}\right)_{3}(3.1$ $\mathrm{ppm})$ and $-\mathrm{C}_{6} \mathrm{H}_{5}(7.2 \mathrm{ppm})$ were observed. The mole fraction unit of MPC in the polymer was 0.62 which was determined from the NMR spectroscopy, that is, the ratio of the integration of the $-\mathrm{N}^{+}\left(\mathrm{CH}_{3}\right)_{3}$ peak and $-\mathrm{C}_{6} \mathrm{H}_{5}$ peak. The $M_{n}$ and $M_{w}$ were $1.0 \times 10^{4}$ and $1.6 \times 10^{4}$, re- spectively. The obtained poly(MPC-co-St) was soluble in water, PBS and ethanol.

Surface Tension Measurement of Poly (MPC-co-St) Aqueous Solution

It is well known that the surface tension of water is very sensitive to the nature of the solute. ${ }^{14}$ For example, dissolution of some inorganic ions increases the surface tension of water, whereas general organic compounds induce lowering of the surface tension. This lowering effect depends on the molecular structure or aggregation state of the solute, which is clearly indicated in aqueous solutions of the surfactant or amphiphilic compound. Therefore, the measurement of the surface tension of the polymer solution is one of the useful methods to evaluate the conformation of the polymer in water.

Figure 3 indicates the polymer concentration dependence of the surface tension observed in an aqueous solution of water-soluble poly(MPC-co-St). The surface tension of water was $72 \mathrm{dyn} \mathrm{cm}^{-1}$, and this value did not change when the poly (MPC-co-St) concentration reached $0.001 \mathrm{wt} \%$. However, the surface tension began to drastically decrease at $0.01 \mathrm{wt} \%$.

In the case of poly(MPC), the surface tension of the solution was higher than $70 \mathrm{dyn}^{-1}$ from $10^{-4} \mathrm{wt} \%$ to $1.0 \mathrm{wt} \%$. The surface tension was not dependent on the concentration of the poly(MPC). ${ }^{15,16}$ The concentration dependence of the surface tension of the poly(MPC-co$\mathrm{St}$ ) aqueous solution indicates the aggregation of polymer chains in the solution. This is due to the effect of the hydrophobic St units in the poly(MPC-co-St).

Measurement of the Amounts of Non-Specific Adsorption of Enzyme-Antibody Conjugate

Figure 4 shows the non-specific adsorption amount of the HRP-IgG conjugate. When compared with BSA and casein used as a blocking reagent, the poly(MPC-co-St) blocking agent had almost the same level function for the non-specific adsorption. Without immobilized antibody (only microtiter plate), when the HRP-IgG solution was pipetted into wells treated with these blocking reagents, poly(MPC-co-St) showed also equal function (data not shown). This is because the hydrophobic units in poly(MPC-co-St) could adsorb on the microtiter plate surface and the MPC units prevented non-specific adsorption of HRP-IgG conjugate.

\section{Effect of Blocking Reagents on the Amount of Product}

Figure 5 shows the amount of product by the reaction between the HRP and OPD for $10 \mathrm{~min}$. The maximum wavelength of the absorption spectra of the product is $492 \mathrm{~nm}$. Based on the measurement of the amount of non-specific adsorption of enzyme-antibody conjugate, poly(MPC-co-St), BSA and casein had almost equal ability for prevention (Figure 4). However, for the case of measuring the activities of immobilized antibody using mouse IgG as an antigen, BSA had a higher absorbance compared with other blocking reagent $(p<0.01)$. The difference between poly(MPC-co-St) and casein was not significant $(p>0.01)$.

Measurement of the Remaining Activities of Immobilized Antibody 


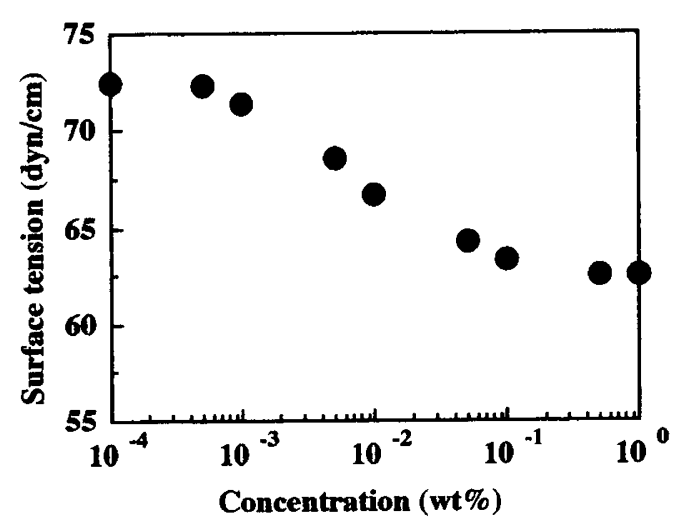

Figure 3. Poly(MPC-co-St) concentration dependence on surface tension of aqueous solution.

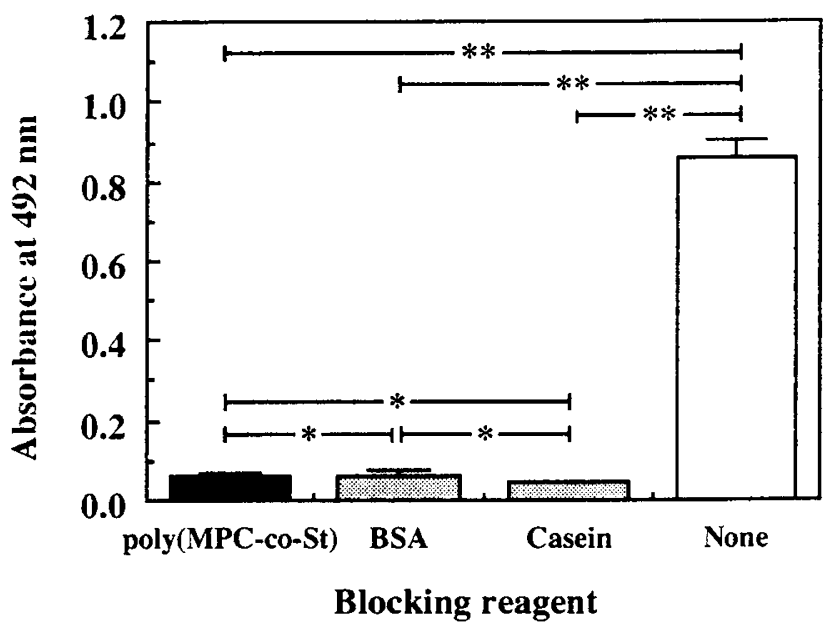

Figure 4. The amount of non-specific adsorbed enzyme-antibody conjugate. Concentration: $[$ poly $(\mathrm{MPC}-\mathrm{co}-\mathrm{St})]=0.01 \mathrm{wt} \%,[\mathrm{BSA}]$ and $[$ Casein $]=$ $0.1 \mathrm{wt} \%$, average $\pm \mathrm{SD}(n=4) . *: p>0.01, * *: p<0.01$

Figure 6 shows the remaining activities of the immobilized antibody. When the BSA and casein were used as blocking reagents, the immunological activity decreased $47.9 \%$ and $65.3 \%$ of the initial value, respectively. However, in the case of the $0.1 \mathrm{wt} \%$ poly(MPC-co-St) solution, the activity remained at $76.1 \%$ of its initial value. Moreover, when the $0.01 \mathrm{wt} \%$ poly(MPC-co-St) solution was applied, the activity remained at $91.2 \%$ of its initial value. It has already been reported that their secondary structure of the adsorbed proteins on the MPC surface was maintained. ${ }^{10}$ Our previous article reported that when the $0.1 \mathrm{wt} \%$ BSA solution and $0.1 \mathrm{wt} \%$ casein solution were used as stabilizers of the enzyme-antibody conjugate, the immunological activity of the enzyme-antibody conjugate decreased to about $10 \%$ and $29 \%$ of their initial values after 37 days, however, in $0.1 \mathrm{wt} \%$ and $1.0 \mathrm{wt} \%$ poly(MPC-co-St) solution case, the activity remained at $74 \%$ and $92 \%$ of their initial values, respectively. ${ }^{11}$ These results demonstrate that the poly(MPCco-St) solution maintained the immunological activity of the enzyme-antibody conjugate.

When differential scanning calorimetric analysis of the protein solution was carried out, the peaks based on

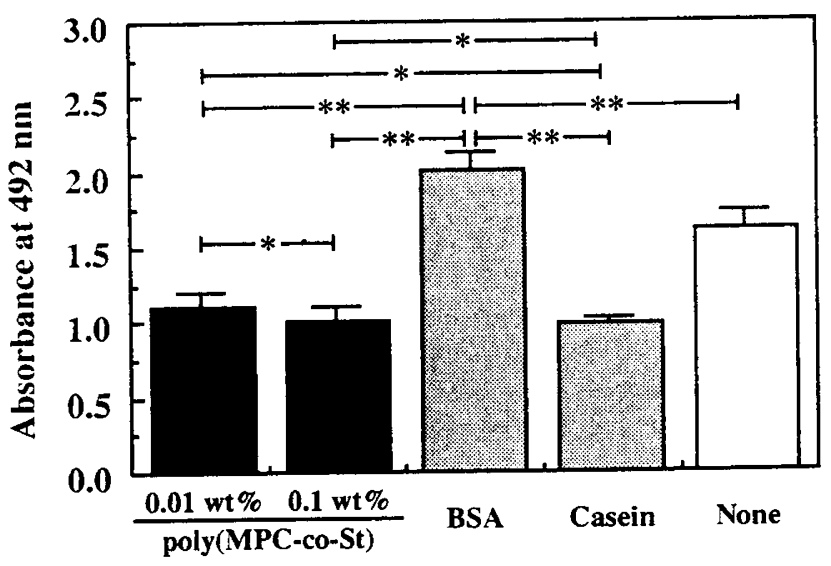

Blocking reagent

Figure 5. The amount of product by HRP-OPD reaction at $25^{\circ} \mathrm{C}$ for $10 \mathrm{~min}$. Concentration: [poly(MPC-co-St)] $=0.01 \mathrm{wt} \%$ and $0.1 \mathrm{wt} \%$, [BSA] and $[$ Casein $]=0.1 \mathrm{wt} \%$, average $\pm \operatorname{SD}(n=6) . *: p>0.01, * *: p<0.01$

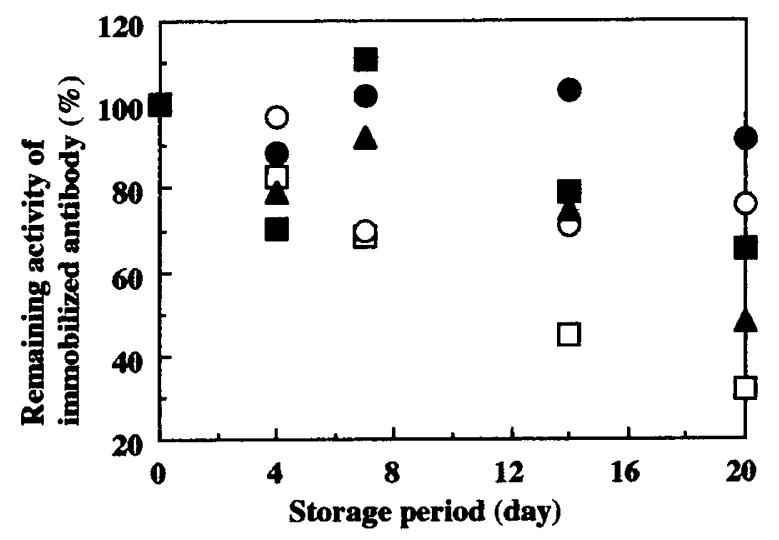

Figure 6. Remaining activities of immobilized antibody that was stored at $40^{\circ} \mathrm{C}$ in the presence of various blocking reagents. Poly(MPC-co-St): $(0.01 \mathrm{wt} \%), \bigcirc(0.1 \mathrm{wt} \%)$, BSA: $\boldsymbol{\Delta}(1.0 \mathrm{wt} \%)$, Casein: $\mathbf{D}(1.0 \mathrm{wt} \%)$, None: $\square$.

the thermal denaturation of proteins are observed at about $55^{\circ} \mathrm{C}-65^{\circ} \mathrm{C} .{ }^{17}$ However, poly(MPC-co-St) solutions without protein did not show any peak in this temperature range.

Park et al. reported one possible of mechanism for understanding protein adsorption on the polymer surface. ${ }^{18}$ As demonstrated in Figure 7, when protein adsorbs on the solid phase, hydrophobic interaction between the protein and the solid phase need to be immobilized. When the BSA (or casein) was used as blocking reagents, the activities of the immobilized antibody decreased after long storage. This phenomenon due to the conformational change in the BSA (or casein) and immobilized IgG, that is, the hydrophobic part of these proteins are exposed and contact the solid phase surface. However, in case of the poly(MPC-co-St), the conformational change dose not occur and maintain the confomation of immobilized IgG. 


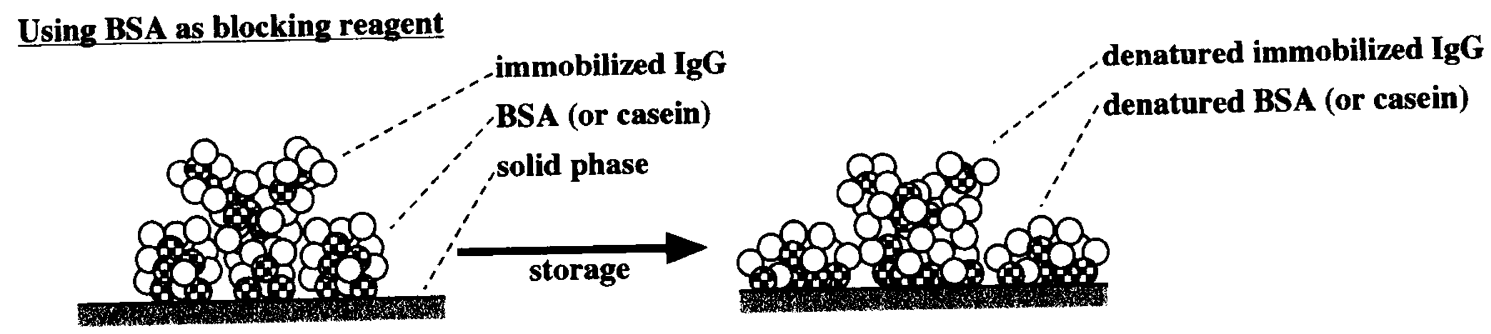

\section{Using poly(MPC-co-St) as blocking reagent}
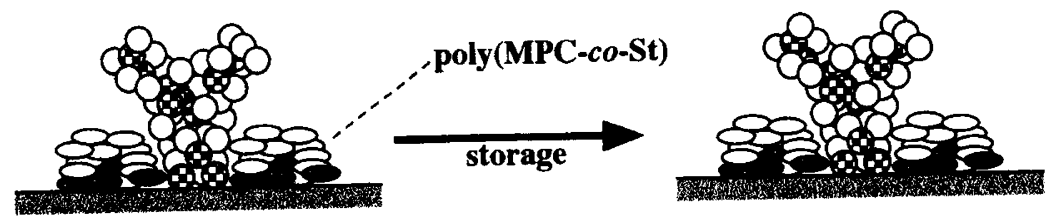

Figure 7. Denaturaion mechanism of immobilized IgG using BSA as a blocking reagent.

\section{CONCLUSIONS}

The HRP and the OPD was used for labeling the antibody and substrate of HRP, respectively. If there are other combinations of the enzyme and substrate, poly(MPC-co-St) will have enough functions to prevent the non-specific adsorption of the enzyme-antibody conjugate and maintain the activities of the immobilized antibody. The proteins (BSA and casein) have the danger of cross-reaction and biohazards because BSA and casein are made of bovine serum and bovine milk, respectively, containing another protein. In case of poly(MPC-co-St), there are no cross-reactions and no danger of biohazards because poly(MPC-co-St) is synthetic polymer not containing another protein. From these results, it is concluded that the poly(MPC-co-St) is superior to proteins as a blocking reagent and is an effective reagent for the immunoassay system.

Acknowledgments. The authors are grateful to members of NOF Corporation, Tokyo, Japan, Dr. Kenshiro Shuto, Mr. Satoshi Yamada, and Mr. Ryota Ando for their useful comments during this study.

\section{REFERENCES}

1. B. H. Anderton and R. C. Thorpe, Immunol. Today, 2, 122 (1980).
2. G. B. Wisdom, "Enzyme-Immunoassay" 1976, Vol. 22, p 1243.

3. M. Osborn, R. E. Webster, and K. Weber, J. Cell. Biol., 77, R 27 (1978).

4. A. G. Farr and P. K. Nakane, J. Immunol. Method., 47, 129 1981.

5. L. Orci, Diabetologia, 28, 528 (1985).

6. E. Ishikawa, M. Imagawa, S. Hashida, S. Yoshitake, Y. Hamaguchi, and T. Ueno, J. Immunoassay, 4, 209 (1983).

7. E. Isikawa, M. Imagawa, and S. Hashida, Develop. Immunol., 18 (Immunoenzym. Tech.), 219 (1983).

8. M. Imagawa, S. Yoshitake, Y. Hamaguchi, E. Isikawa, Y. Niitsu, I. Urushizaki, R. Kanazawa, S. Tachibana, M. Nakazawa, and H. Ogawa, J. Appl. Biochem., 4, 41 (1982).

9. K. Ishihara, N. P. Ziats, B. P. Tierney, N. Nakabayashi, and J. M. Anderson, J. Biomed. Mater. Res., 25, 1397 (1991).

10. K. Ishihara, H. Nomura, T. Mihara, K. Kurita, Y. Iwasaki, and N. Nakabayashi, J. Biomed . Mater. Res., 39, 323 (1998).

11. S. Sakaki, K. Ishihara, and N. Nakabayashi, J. Biomed . Mater. Res.,47, 523 (1999).

12. K. Ishihara, T. Ueda, and N. Nakabayashi, Polym. J., 22, 355 (1990).

13. M. Kojima, K. Ishihara, A. Watanabe, and N. Nakabayashi, Biomaterials, 12, 121 (1991).

14. D. J. Shaw, "Introduction to colloid and surface chemistry.," 3rd ed. , Butterworths, London, 1980.

15. K. Ishihara, T. Tsuji, Y. Sakai, and N. Nakabayashi, $J$. Polym. Sci., Part A: Polym. Chem ., 32, 859 (1994).

16. K. Ishihara, Y. Iwasaki, and N. Nakabayashi, Polym. J., 31, 1231 (1999).

17. J. W. Donovan and R. A. Beardslee, J. Biol . Chem ., 250, 1966 (1975).

18. D. R. Lu, S. J. Lee, and K. Park, J. Biomater. Sci. Polym. Ed., 3, 127 (1991). 